\section{PEAK FLOW RATES IN NORMAL AND ASTHMATIC CHILDREN}

BY

P. J. D. HEAF, M.D., M.R.C.P.

AND

\section{P. M. S. GILLAM, M.B., M.R.C.P. D.Obst.R.C.O.G. \\ From University College Hospital, London}

The measurement of a single forced expiration is now widely accepted as a method of assessing ventilatory capacity. The usual technique is to record the expiration on a spirometer with a rotating drum or a timing device, and to measure the amount of air expired in the first second (F.E.V.1) plus the total forced vital capacity (F.V.C.). The ratio F.E.V./F.V.C. is then expressed as a percentage, and gives a measure of the presence and degree of ventilatory deficiency. In normal subjects this percentage is 75 or more. F.E.V..$_{1}$ is well correlated with maximum voluntary ventilation (M.V.V.). Wright and McKerrow (1959) have described the measurement of the maximum expiratory flow rate (or "peak flow rate"). This test consists simply of measuring a single maximum puff on a portable meter. The Wright peak flow meter has now been used on an extensive scale in adults (Higgins, 1957 ; Lockhart et al., 1960 ; Tinker, 1961).

These workers have found a good correlation between the peak flow rate (P.F.R.) and the F.E.V. Prime (1960) has stated that the P.F.R. is better correlated with M.V.V. than F.E.V. Most workers have found that the P.F.R. does not produce such repeatable results as the F.E.V.. , but the simplicity of the test outweighs this.

We present here some results of the use of the test in children, and in particular its application to the management of children with asthma. The simplicity of the procedure is, of course, of even greater importance in children than in adults. It is difficult to get a spirometric tracing from a child below the age of 5 , especially if the child is ill. We have had no difficulty in getting good and repeatable peak flow readings from children down to the age of 3 , and sometimes younger.

\section{Method}

We were provided by Dr. B. M. Wright with a peak flow meter which had been modified by putting in a lighter spring (see Wright and McKerrow (1959) for an explanation of the principles involved). This meter was calibrated by putting it in series with a Vickers pneumotachograph and recording puffs blown through the two. Comparison of the curves produced by the pneumotachograph in this way with those produced by puffing through the pneumotachograph alone showed that the peak flow meter did not affect the response of the pneumotachograph. It was also shown that the presence of the pneumotachograph did not affect the peak flow meter reading for steady flow. The pneumotachograph was calibrated using a rotameter. In this way a meter which would record flow rates of 30-140 $1 . /$ min. was prepared. All readings above this range were made with an adult meter (Airmed No. 441). A few of the early readings in the series were made with the pneumotachograph alone. The children were given two or three practice puffs, and then the average of the next three puffs was recorded.

\section{Results}

Fig. 1 shows the relationship of the P.F.R. and F.E.V. ${ }_{1}$ in normal and asthmatic children; some of the latter were wheezing and others not. The

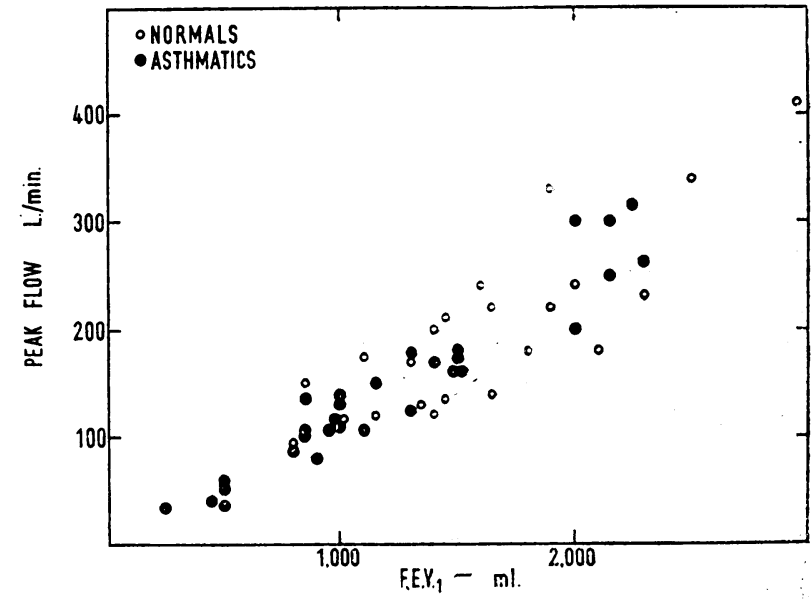

Fig. 1.-Relationship of P.F.R. and F.E.V., in normal and asthmatic children.

ages of the children were 5 years 9 months to 14 years 3 months. The data were collected from 40 children. The readings for normal children were all from different subjects. Some of our asthmatic patients provided several points at different stages during their attacks or between attacks. The correlation is good, the correlation coefficient being 0.83 in normals and 0.96 in abnormals. It was not possible to make the comparison in children below the age of 5 because of the difficulty in obtaining F.E.V., readings.

Fig. 2 shows readings from 86 normal children between the ages of $2 \frac{1}{2}$ and 14, compared with those

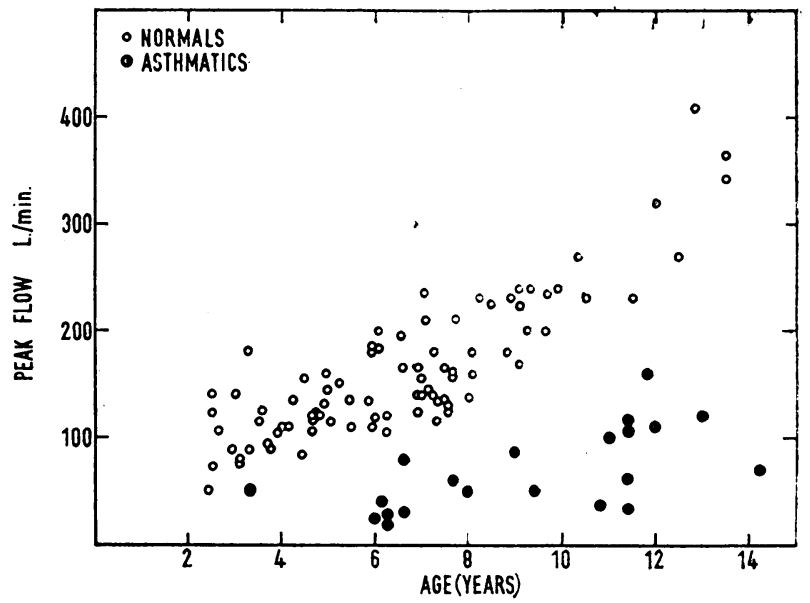

FIG. 2.-Comparison of peak flow readings from normal and asthmatic children.

from 21 children in an asthmatic attack. P.F.R. is plotted against age. Our normal values show good correlation with age $(\mathrm{P}<0.001)$, weight $(\mathrm{P}<0.001)$, and height $(\mathrm{P}<0.01)$. 
Table I shows how the P.F.R. can be used as an objective measure of a child's response to treatment. This patient is a chronic asthmatic on long-term steroid treatment. Clinical estimation of the degree of bronchospasm over a period of months is extremely difficult, and it is in cases such as these that an objective measurement is most valuable.

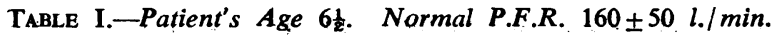

\begin{tabular}{c|c}
\hline Date & Peak Flow Rate \\
\hline $13 / 3,61$ & $301 . / \mathrm{min}$. \\
$8 / 561$ & 40 \\
$2 / 1061$ & 100, \\
$3 ! 1 / 62$ & $145, "$, \\
\hline
\end{tabular}

Table II shows the day-to-day progress of another patient on long-term steroid treatment who was admitted in status asthmaticus. His dose of steroid was greatly increased and he responded so well that on the third day it was cut down again, in fact rather too soon.

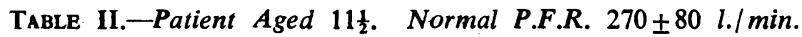

\begin{tabular}{|c|c|c|c|c|}
\hline & & & $\begin{array}{l}\text { Peak Flow before } \\
\text { Isoprenaline }\end{array}$ & $\begin{array}{l}\text { Peak Flow after } \\
\text { Isoprenaline }\end{array}$ \\
\hline $\begin{array}{l}\text { 1st day } \\
\text { 2nd ", } \\
\text { 3rd ", } \\
\text { 4th ", }\end{array}$ & $\begin{array}{l}\cdots \\
\therefore \\
\therefore\end{array}$ & $\begin{array}{l}\cdots \\
\cdots \\
\cdots\end{array}$ & $\begin{array}{l}301 . / \mathrm{min} . \\
105 \% " \\
115 \% \\
55 ",\end{array}$ & $\begin{array}{l}35 \mathrm{l} / \mathrm{min} . \\
160 \% \\
180 \% \\
105 ",\end{array}$ \\
\hline
\end{tabular}

\section{Discussion}

The peak flow meter is undoubtedly a useful clinical instrument. It can be taken to the patient's bedside; it can be used in the out-patient department and consulting-room, where more-complicated and expensive machinery is not available. It is easy to use even in young children who may not be able to manage any other test, and it gives a worth-while objective measure of ventilatory capacity. However, there is a wide range of normality, so that the test is more useful in showing change in a given patient than as an absolute measure. We do not believe that it should replace spirometry except in the circumstances described.

When we started using this test no normal figures for children had been published except very few by Avery (1961). Nairn et al. (1961) have published results in a large number of schoolchildren between the ages of 6 and 18. We have therefore concentrated rather more on younger children. In the age-groups where we overlap, our mean values are lower than theirs by $501 . / \mathrm{min}$. There are various possible reasons for this. Their subjects were normal schoolchildren, whereas ours were healthy children attending paediatric follow-up and welfare clinics and may therefore have been a less robust group. It is possible that London children have lower peak flow rates than Scottish children. M. H. Wadahn (1961, personal communication) in a similar group to ours, has also found lower mean values than the Scottish workers. Also, Nairn et al. tested their children in groups with competitions and prizes, whereas ours were tested singly with only vocal encouragement. In these age-groups we were using an adult peak flow meter, and there is undoubtedly some variation in response from meter- to meter (Wright and McKerrow, 1959). Any or all of these factors may have been. responsible, for: the difference.
We thank Dr. Bernard Schlesinger and Dr. Bonham-Carter for permission to study their patients, and Dr. M. H. Wadahn for help with the statistics. Dr. B. M. Wright has been most helpful with advice, as well as constructing and lending us a meter. (Airmed Ltd. are in the process of developing a commercial meter for use in children.)

REFERENCES

Avery, M. E. (1961). Report of 37th Ross Conference on Pediatric Research

Higgins, I. T. T. (1957). Brit. med. J., 2, 1198.

Lockhart, W., Smith, D. H., Mair, A., and Wilson, W. A. (1960). Ibid., 1, 37 .

Nairn, J. R., Bennet, A. J., Andrew, J. D., and Macarthur, P. (1961). Arch. Dis. Childh., 36, 253.

Prime, F. J. (1960). Brit. med. J., 1, 423.

Tinker, C. M. (1961). Ibid., 1, 1365.

Wright, B. M., and McKerrow, C. B. (1959). Ibid., 2, 1041.

Preliminary Communications

\section{Dermal Leishmaniasis in British Honduras : Some Host-reservoirs of $\mathbf{L}$. brasillensis mexicana $x$}

The dog has long been known as a host-reservoir of Leishmania donovani in endemic areas of kala-azar in the Mediterranean, China, the Caucasus, and South America; jackals have also been incriminated (Adler and Theodor, 1957, review). Deane and Deane (1955), in Brazil, found the fox (Urocyon parvidens) to harbour visceral leishmaniasis.

Similarly, dogs have been found naturally infected with L. tropica in Iran and Iraq (Adler and Theodor, 1957, review). In Turkmenistan intensive foci of human L. tropica infections have been found to be closely associated with infected wild gerbils and groundsquirrels (Latischev and Kriukova, 1941; Shekhanov and Suvorova, 1960). The authors suggested that Phlebotomus caucasicus and $P$. papatasi, living in the burrows of these rodents, maintain the infection among them. $P$. papatasi was thought to act as the vector of the parasite from rodent to man.

Much less is known about the host-reservoirs of the different forms of $L$. brasiliensis, the causative organism responsible for the variety of cutaneous leishmaniasis throughout Latin America. In Brazil Forattini and Santos (1955) found leishmania-like bodies in sores on a specimen of Cuniculus paca (a large forest rodent), but they could not be certain of the exact nature of the organisms. In Panama L. brasiliensis has been isolated from $10.5 \%$ of 200 spiny rats (Proechimys semispinosus) by the culture of heart-blood in N.N.N. medium (Hertig et al., 1958). Curiously enough, the parasite could not be detected in the viscera of these animals or in the tissues of sub-inoculated spiny rats and hamsters.

Some Latin American workers (Pessoa and Barreto, 1948 ; Biagi, 1953) appear to attach little importance to the role of wild animals as reservoirs. of infection for man. As stressed by Garnham and Lewis (1959); however, "The epidemiology of the disease . . . clearly suggests that it is of the nature of a zoonosis. The old human case could constitute a source of infection, but the organisms in chronic lesions are extremely scanty, 